\title{
Lithium intoxication presenting as a mixed misidentification syndrome
}

\author{
S.G. Potts \\ Registrar, Maudsley Hospital, Denmark Hill, Camberwell, London SE5 8AZ, UK \\ Correspondence: S. G. Potts, Research Fellow, University Department of Psychiatry, Royal \\ Edinburgh Hospital, Morningside Park, Edinburgh EH10 5HF, UK
}

A case is reported of lithium intoxication presenting with a mixed misidentification syndrome including features of Capgras syndrome. CT scanning showed cerebral atrophy, greater on the right, consistent with earlier evidence, suggesting that misidentification syndromes are more common with right hemisphere lesions.

\section{INTRODUCTION}

Misidentification syndromes, by their bizarre and dramatic nature, arouse in psychiatrists an interest out of keeping with their apparent rarity, and attract the application of eponyms. The term "Capgras syndrome" denotes the delusional misidentification of familiar individuals as imposters or doubles (Capgras and Reboul-Lachaux, 1923); and "Fregoli Syndrome" denotes the delusional misidentification of unfamiliar individuals as friends or intimates in altered form (Courbon and Fail, 1927). Various other misidentification syndromes have been described, including "reduplicative paramnesia", or the delusional misidentification of the subject's physical surroundings (Pick, 1903). Förstl and colleagues have recently argued that these conditions are best regarded as symptoms rather than syndromes, and that together they represent a "family of personal object and environment misidentifications with overlapping aetiologies and associations [rather] than a collection of discrete diagnostic categories" (Förstl et al., 1991).

Case reports have described such symptoms occurring in a wide variety of medical and psychiatric conditions (Cummings, 1985), and following treatment with a wide variety of different drugs, including psychotropic agents such as thioridazine (Waziri, 1978): but they have not, so far, been associated specifically with lithium intoxication.

Among psychotropic agents, lithium is the drug with the narrowest therapeutic index (Cooper, 1980), and the characteristic manifestations of toxicity are wide ranging and well-recognised (British Medical Association and Royal Pharmaceutical Society of Great Britain, 1991). Lithium is known to affect most body systems, and has many neurotoxic effects (Tyrer and Shopsin, 1980), including acute organic brain syndromes or delirium
(Agulnik et al., 1972). A case in which a combination of Capgras syndrome and delusional misidentification of surroundings arose in a patient with toxic lithium levels is now reported.

\section{CASE REPORT}

A 62-year-old retired male academic of considerable distinction, was referred as an emergency by his GP, who described him as "confused and deluded". His wife described a history of variable low mood, mild memory impairment and intermittent heavy drinking, since the death of his beloved sister, a year previously, and a more recent one-month history of increased depression, memory impairment and disorientation, with irritability, disturbed sleep, vivid dreams, and problems with basic self-care such as dressing and shaving. Although he could not describe his experiences at the time, he later recounted them in retrospect, and described how disturbing they were. Familiar surroundings, including his home, were no longer familiar to him. He believed all the furniture had been changed, although it looked the same. He believed his wife had been replaced by an unfamiliar imposter who was "playing games" with him. He felt trapped, and threatened, particularly at night, when "this strange woman got into bed with me". He explained some of his nocturnal wandering round the house as an attempt to escape.

He had a family history of depression affecting his mother and maternal grandmother (both of whom committed suicide), as well as a sister and a nephew. He came from a working class background, and after national service attained academic distinction, going on to pursue an academic career and to marry twice. He had suffered three

Behavioural Neurology . Vol 5 . 1992 
a

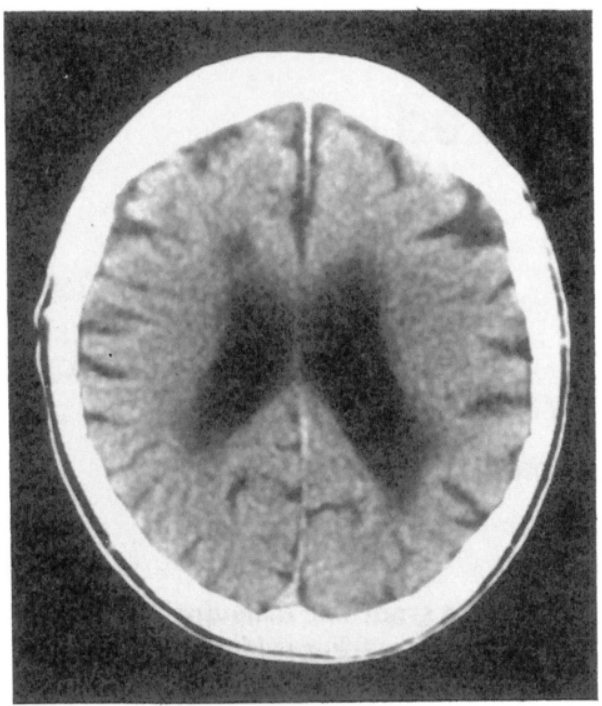

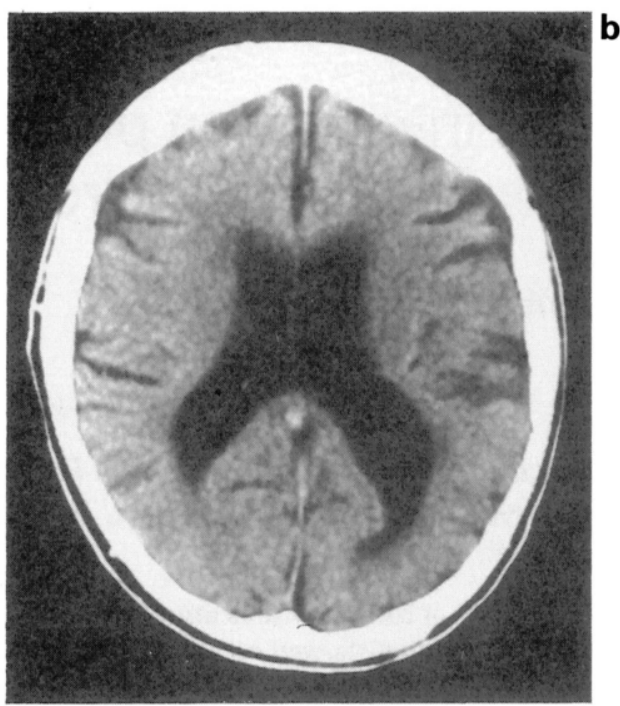

FIG.1a, b. CT Scan showing cerebral atrophy and asymmetrical ventricular enlargement.

episodes of depression requiring inpatient treatment and ECT, most recently in 1974, since when he had been maintained on lithium alone. He had never had a manic episode. He had drunk heavily at times in the past when under pressure, but without evidence of alcohol-related harm or dependence. He was otherwise well.

Mental state examination on presentation revealed poor self-care, irritability, restlessness, and a preoccupation with domestic finance, though he did not seem especially depressed. He described visual hallucinations, seeing his surroundings bathed in a deep blue light. He co-operated poorly with cognitive testing, but there was evidence of word-finding difficulties, an uncharacteristic stammer, dressing apraxia, temporospatial disorientation, poor concentration, and impairment of short and long-term memory. He scored $5 / 10$ on the Abbreviated Mental Test (AMT-Hodkinson 1972), but did not complete the MiniMental State (MMSE-Folstein et al., 1975).

Physical examination demonstrated some over-salivation and longstanding exophthalmos, but no cardiovascular, respiratory or gastro-intestinal abnormalities, and in particular no stigmata of liver disease. All movements, including his gait, were very slow and deliberate. There was a pill-rolling tremor affecting both upper limbs equally, but tone and reflexes were normal. No ophthalmoplegia, nystagmus or other cranial nerve abnormalities were observed.

Investigation revealed a macrocytosis (MCV 103.9), with an otherwise normal blood profile. His ESR, electrolytes, LFTs, TFTs, B12, folate and VDRL were all normal or negative. His CT scan (see Fig. 1a, b) showed bifrontal sulcal widening and asymmetric ventricular enlargement.

Unexpectedly his lithium level was found to be in the toxic range at $2.1 \mathrm{mmol} / \mathrm{l}$. It had last been checked 4 months previously, when it was satisfactory at $0.9 \mathrm{mmol} / \mathrm{l}$. He had been on the same dose ( $900 \mathrm{mg}$ at night) for at least 4 years, which generally gave him serum levels at the upper end of the therapeutic range, and he took no other medication apart from very occasional diazepam. There had been no recent intercurrent illness.

Lithium was immediately stopped, and he was closely observed. Three days later, when the level was still 0.8 $\mathrm{mmol} / \mathrm{l}$, his condition was unchanged, but after a further 3 days all his presenting symptoms had improved, and he was able to give the retrospective description of his misidentification experiences recounted above. Ten days after stopping lithium all symptoms had completely resolved, and he was back to his usual self, but there was still evidence of mild cognitive impairment (AMT 9/10, MMSE 22/30). One month later he remained well, and his scores had improved further (AMT 10/10, MMSE 29/30), the only deficit being a longstanding difficulty remembering names. He then underwent full psychometric testing, in which he performed exceptionally well, with no evidence of impairment. Four months later he remained free of symptoms, but there was evidence from his MCV and GGT of a return to excess drinking, possibly in response to shoulder pain arising from radiologically-proven cervical spondylosis.

\section{DISCUSSION}

The patient displayed symptoms of a mixed misidentification syndrome with two components. One, the delusional belief that his wife had been replaced by an imposter, qualifies as an instance of Capgras syndrome: 
but the other, the delusional belief that his familiar surroundings had been changed, does not amount to an instance of reduplicative paramnesia, because there was no definite element of duplication.

The close temporal correlation in this case between the rise and fall in lithium levels, and the emergence and resolution of the misidentification symptoms, provides evidence for a causal link between them. The existence of such a causal link is not surprising in view of the wideranging neurological and psychiatric effects of lithium and the many known causes, including drug reactions, of misidentification symptoms, but there is only one previous report of an association between lithium administration and misidentification phenomena (Canagasabey and Katona, 1991). In that case the specificity of the association is in doubt because the lithium concentration was only marginally outside the therapeutic range at 1.12 $\mathrm{mmol} / \mathrm{l}$, and because another psychotropic agent, the monoamine oxidase inhibitor tranylcypromine, was administered and withdrawn in parallel with lithium. Monoamine oxidase inhibitors have not been associated with misidentification syndromes as such; but they are known to cause a variety of mental state disturbances (Reynolds, 1982); and florid paranoid psychosis secondary to another monoamine oxidase inhibitor, phenelzine, has been reported (Sheehy and Maxmen, 1978).

This patient's high alcohol intake, past and present, may have played a part in the development of his symptoms, so that lithium exerted its effects on a brain already damaged by alcohol. Although alcohol abuse alone has not been directly implicated as a cause of Capgras syndromes, it is often described in association with other possible causes of misidentification syndromes (Hakim, 1978: Quinn, 1981). Alternatively alcohol may have played a more immediate role, through dehydration or other metabolic disturbances, which might explain why lithium toxicity developed while the dose remained unchanged.

There is evidence from the CT scan of cerebral atrophy, which could be explained by the effects of alcohol, or possibly by a direct neurotoxic effect of prolonged exposure to lithium in high (but still therapeutic) levels. The CT scan also shows evidence of asymmetry, with the right lateral ventricle larger than the left, especially in the occipital horn. In their review of 260 cases of misidentification syndromes, Forstl and colleagues report that of 80 patients who had undergone CT scanning, 39 (49\%) displayed cortical atrophy; and in the 19 cases where abnormalities were lateralised, the right hemisphere was the affected side in all but one (Forstl et al. 1991). This lateralisation to the right is reported by other reviewers (Hakim, 1978; Quinn, 1981).

Also of interest, given the severity of the cognitive disturbances and psychotic symptoms, is the relative lack of other, more familiar, features of lithium toxicity, such as oculomotor or gastro-intestinal disturbances, so that the finding of an elevated lithium level was unexpected. Another recently reported case (Goddard et al., 1991) showed that severe lithium intoxication can present primarily as behavioural disturbance, thus raising diagnostic difficulties in differentiating the effects of intoxication from the underlying psychiatric illness. This demonstrates, once again, the protean manifestations of lithium intoxication, and the need to check the levels in any patient on lithium presenting with unfamiliar symptoms, whether physical or psychological.

\section{Acknowledgements}

I am grateful to Professor R. Levy for his permission to report the case, and his helpful comments; to Dr R. Woods for conducting the neuropsychometric testing; and to Drs H. Förstl and A. Burns for their constructive criticism.

\section{REFERENCES}

Agulnik, P.L., Dimascio, A. and Moore, P. (1972). Acute brain syndrome associated with lithium therapy. American Journal of Psychiatry, 129, 621-623.

British Medical Association and Royal Pharmaceutical Society of Great Britain (1991). British National Formulary, 21, $140-141$.

Canagasabey, B. and Katone, C.L.E. (1991). Capgras syndrome in association with lithium toxicity. British Journal of Psychiatry, 159, 879-881.

Capgras, J. and Reboul-Lachaux, J. (1923). L'illusion des "sosies" dans un delire systematise chronique. Bulletin de la Societe Clinique de Medecine Mentale, 2, 6-16.

Cooper, T.B. (1980). Monitoring lithium dose levels: estimation of lithium levels in the blood. In Handbook of Lithium Therapy (Ed. F.N. Johnson). MTP Press, Lancaster.

Courbon, P. and Fail, G. (1927). Syndrome "d'illusion de Fregoli" et schizophrenie. Bulletin de la Societe Clinique de Medecine Mentale, 15, 121-124.

Cummings, J.L. (1985). Organic delusions: phenomenology, anatomical correlations, and review. British Journal of Psychiatry, 146, 184-197.

Folstein, M.F., Folstein, S.E. and McHugh, P.R. (1975). Minimental state. A practical method for grading the cognitive state of patients for the clinician. Journal of Psychiatric Research, 12, 189-198.

Förstl, H., Almeida, O.P., Owen A.M., Burns, A. and Howard, R. (1991). Psychiatric, neurological and medical aspects of misidentification syndromes: a review of 260 cases. Psychological Medicine, 21, 905-910.

Goddard, J., Bloom, S.R., Frockowiak, R.S.J., Pusey C.D., Macdermot, J. and Liddle P.F. (1991). Hammersmith staff rounds: lithium intoxication. British Medical Journal, 302, 1267-1269.

Hakim, H., Verma N.P. and Greiffenstein, M. (1988). Pathogenesis of reduplicative paramnesia. Journal of Neurology, Neurosurgery and Psychiatry, 51, 839-841.

Hodkinson, H.M. (1972). Evaluation of a mental test score for assessment of mental impairment in the elderly. Age and Ageing, 1, 233-238.

Pick, A. (1903). Clinical studies III. On reduplicative paramnesia. Brain, 26, 260-267.

Quinn, D. (1981). The Capgras syndrome: two case reports and a 
review. Canadian Journal of Psychiatry, 26, 126-129.

Reynolds, J.E.F. (Ed.) (1982). Martindale: The Extra Pharmacopeia, 28th Edn. Pharmaceutical Press, London.

Sheehy L.M. and Maxmen J.R. (1978) Phenelzine-induced psychosis. American Journal of Psychiatry, 135, 1422-1423.
Tyrer, S. and Shopsin, B. (1980). Neural and neuromuscular side-effects of lithium. In Handbook of Lithium Therapy (Ed. F.N. Johnson). MTP Press, Lancaster.

Waziri, R. (1978). The Capgras phenomenon: cerebral dysfunction with psychosis. Neuropsychobiology, 4, 353-359. 


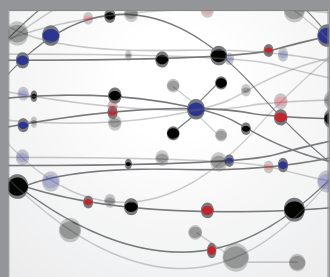

The Scientific World Journal
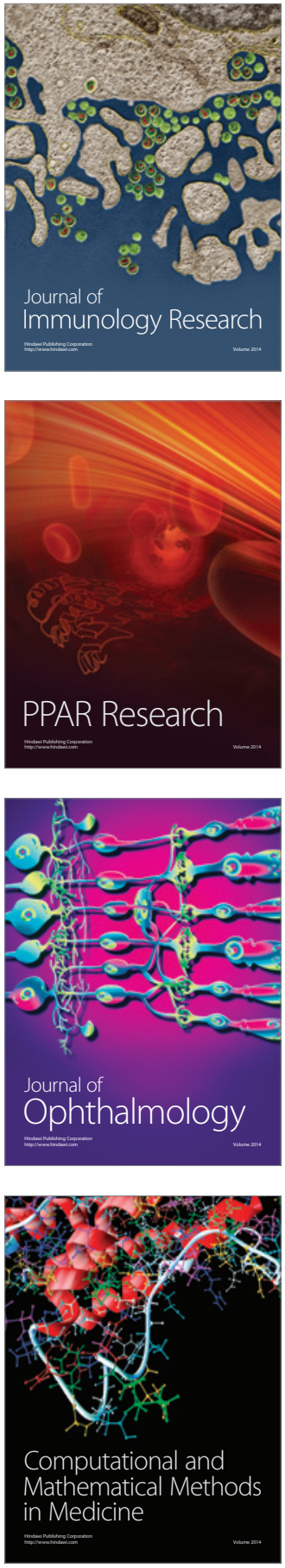

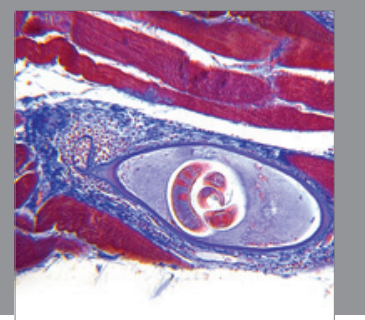

Gastroenterology

Research and Practice
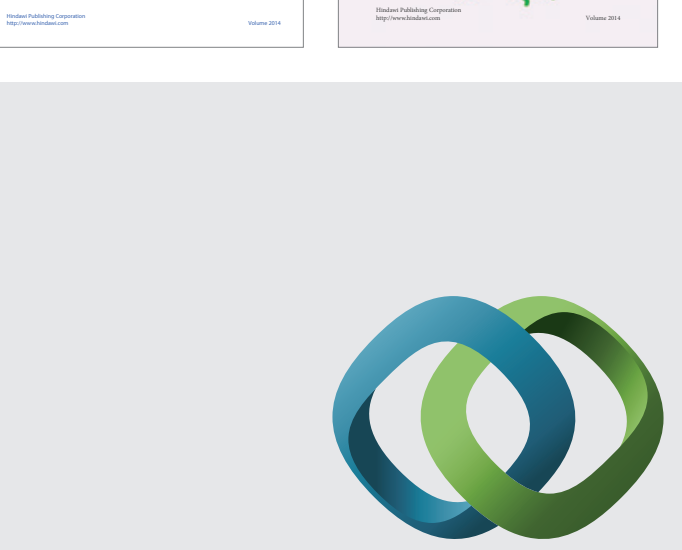

\section{Hindawi}

Submit your manuscripts at

http://www.hindawi.com
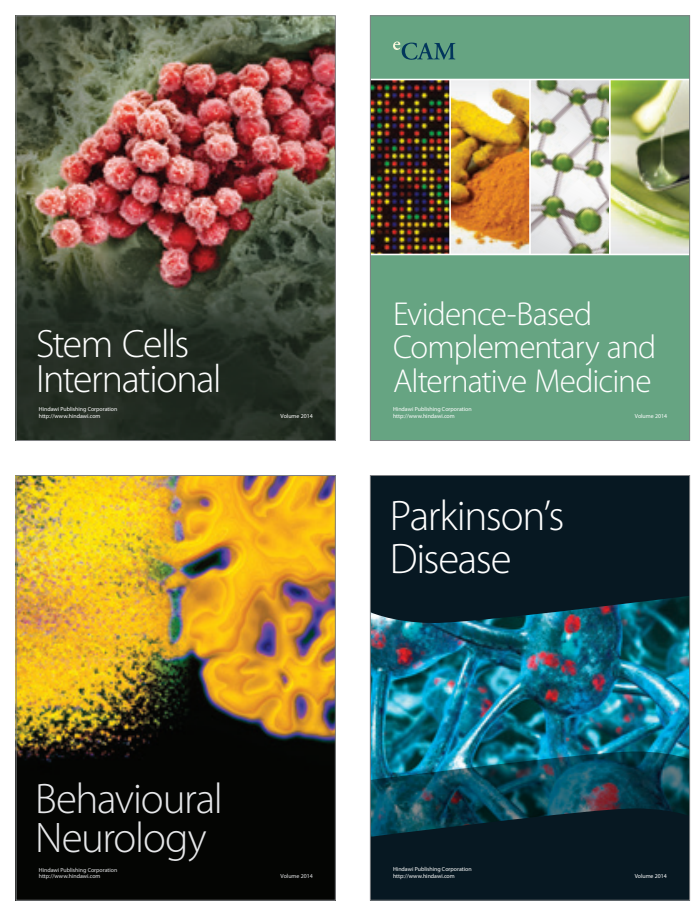

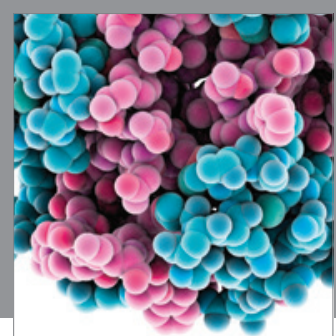

Journal of
Diabetes Research

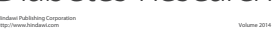

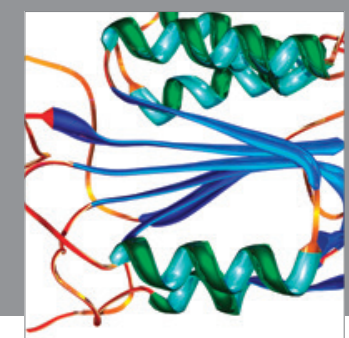

Disease Markers
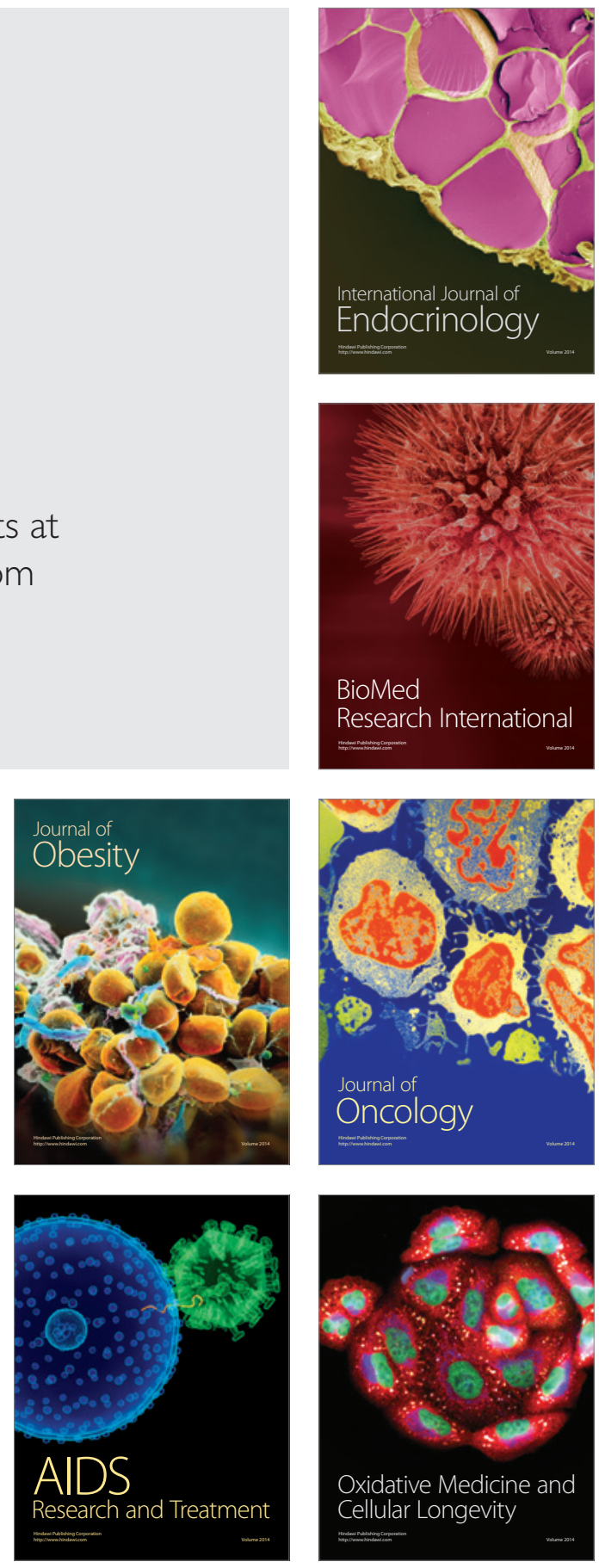